\title{
Motivations and contributions of volunteer groups in the management of invasive alien plants in South Africa's Western Cape province
}

\section{Authors \\ ${ }^{1,2}$ Nolwethu Jubase (1) \\ ${ }^{2,3}$ Ross T. Shackleton (1) \\ 2John Measey (1)}

\section{Affiliations}

'South African National Biodiversity Institute, Kirstenbosch Research Centre, Cape Town, South Africa

${ }^{2}$ Centre for Invasion Biology, Department of Botany \&

Zoology, Stellenbosch University, Stellenbosch, South Africa

${ }^{3}$ Institute of Geography and

Sustainability, University of Lausanne, 1015 Lausanne, Switzerland

\section{Corresponding Author}

Nolwethu Jubase,

e-mail:

N.jubasetshali@sanbi.org.za

\section{Dates}

Submitted: 11 August 2020

Accepted: 13 January 2021

Published: 8 July 2021

\section{How to cite this article:}

Jubase, N., Shackleton, R.T. \& Measey, J., 2021, 'Motivations and contributions of volunteer groups in the management of invasive alien plants in South Africa's Western Cape province', Bothalia 51(2), a3. http://dx.doi. org/10.38201/btha.abc.v51.i2.3

Copyright: (C) 2021. The Authors. Licensee: SANBI. This work is licensed under the Creative Commons Attribution 4.0 International License.
Background: Research and management of biological invasions traditionally focuses on state-operated, large-scale control initiatives, with little emphasis on volunteers. Volunteering can, however, contribute to detection, extirpation and containment of invasive alien plant species (IAPS). Understanding the extent of involvement and motivations of volunteers in IAPS management is important to improve the success of invasive alien species control.

Objectives: In this study we aimed to: 1) identify volunteer groups controlling IAPS in the Western Cape province of South Africa; 2) understand their practices and contributions towards detecting and controlling IAPS; 3) examine volunteer's motivations for controlling IAPS; and 4) identify the challenges individual volunteers and groups face.

Methods: The data were collected using online questionnaires.

Results: In total, we identified 52 volunteer groups. We broadly estimate that half of these groups that participated in the survey clear nearly 5300 ha of land per year with estimated labour contributions of ZAR 5.1 million (equivalent to USD 0.32 million) when aligned with formal state management cost estimates. Most volunteer groups raise their own funds to facilitate their work, however, many suggest support from government entities, landowners and Non-Government Organisations would help. Most volunteers (82\%) detect and report invasive species to their team leaders, citizen science platforms and relevant authorities. Volunteers themselves gain physical and psychological fulfilment and build their social capital by meeting new people.

Conclusion: Our findings point to the valuable contribution of these groups, but also the need for better co-ordination and engagement between volunteer groups and mandated authorities on science, policy and management.

Key words: biological invasions; citizen science; hack groups; invasive alien species; management; stakeholder engagement.

\section{Introduction}

Globally, invasive alien species (IAS) pose a significant and accelerating cost to economies, societies and ecosystems around the world (Pimentel et al. 2005; Jeschke et al. 2014). Humans are responsible for the initial introduction of IAS and their management at later stages (Hulme et al. 2008; Faulkner et al. 2015; Novoa et al. 2018; Shackleton et al. 2019). The rate at which IAS spread and the difficulty of managing them, has resulted in the recognition of the need for collaborations in research and management that enhance the link between science, policy, management and citizens around the world (Novoa et al. 2017; Abrahams et al. 2019). These integrative management approaches 
should include citizens and volunteers to help improve the effectiveness of IAS management over the longterm (Novoa et al. 2018; Dechoum et al. 2019), and support conservation work in times of budgetary constraint (Pagès et al. 2019).

According to Shackleton et al. (2019), there are many ways of involving society in the management of IAS, such as through citizen science and volunteer initiatives to monitor and/or control IAS. Volunteers can make a significant contribution in the local management of IAS at a reasonable cost and their efforts can be sustained over time (Dechoum et al. 2019). Volunteer programmes can also be helpful in increasing public awareness of environmental issues and encourage local people to join groups (Dechoum et al. 2019). More experienced volunteers, or champions, can be very helpful in the early detection of new and satellite infestations. There are various examples of the benefits volunteers can have for IAS management. For example, Dechoum et al. (2019) show that management programmes for invasive pines (Pinus spp.) involving volunteers were effective, and resulted in overall reduction in their abundance and distribution in southern Brazil. Similarly, Delaney et al. (2008) showed a significant contribution by volunteers in detecting the range expansion of Japanese shore crabs (Hemigrapsus sanguineus) in the United States of America. Thomas et al. (2017) demonstrated the value of using citizens to detect invasive animal species using active and passive surveillance in Australia.

Considering the success of volunteers in facilitating IAS management elsewhere in the world, research needs to be undertaken to better understand and document the role of volunteers in the management of IAS in South Africa - which remains a current knowledge gap.

South Africa has major problems with both plant and animal IAS (van Wilgen et al. 2020). Invasive alien plant species (IAPS), in particular, pose a major threat across most of the country and the efforts to control them cost approximately ZAR 2 billion each year (USD 120 million) (van Wilgen et al. 2020). If left unmanaged, the impacts of IAPS on South African ecosystems are likely to increase (Wilson et al. 2020). South Africa has a long history of managing IAPS dating back to 1913 (van Wilgen et al. 2020). The Working for Water (WfW) programme launched by the South African government in 1995 (van Wilgen \& Wannenburgh 2016) is a globally recognised and well-documented control initiative (Richardson \& van Wilgen 2004; van Wilgen et al. 2012). The purpose of this public works programme is to control IAPS as well as create employment opportunities for disadvantaged people (van Wilgen \& Wannenburgh 2016). WfW operates on public and private land, and uses a mixture of biological, chemical and manual control methods (van Wilgen et al. 2020). Furthermore, South Africa has strong legislation, the
National Environmental Management: Biodiversity Act ([NEM: BA] Act 10 of 2004), that underpins the management of IAS.

There is, however, limited research and emphasis on volunteering or private control initiatives in the country (van Rensburg et al. 2017). Understanding the motivations and contributions of volunteers to manage IAS and developing strategies to maintain their enthusiasm and willingness to participate is important to improving successful IAS control. Emphasis should also be placed on understanding the barriers that can negatively affect volunteer participation to guide relevant adaptive responses and policy (Shackleton et al. 2016).

Therefore, this study aims to: 1) identify volunteer groups controlling IAPS in the Western Cape province of South Africa; 2) understand the practices and contributions of volunteer groups towards detecting and controlling IAPS; 3) examine volunteer motivations for managing IAPS; and 4) identify the challenges or barriers that are faced by volunteers when managing IAPS.

\section{Methods}

\section{Study site}

The study was conducted in the Western Cape province, which is located on the southwestern coast of South Africa's Cape Floristic Region (CFR) with a population of approximately 6.8 million people (StatsSA 2019). Almost all of the province's urban population is concentrated in the city of Cape Town, which is also the country's legislative and provincial capital. The Western Cape experiences a Mediterranean climate with hot dry summers and cold rainy winters (Rebelo et al. 2006). The primary vegetation type of the Western Cape is 'fynbos': a highly diverse, evergreen, hard leafed shrubland growing in nutrient poor soils (Rebelo et al. 2006).

The CFR is recognised as a global biodiversity hotspot due to its high levels of plant endemism and diversity (Rebelo 2006). The region is also the most invaded terrestrial area in South Africa, especially by IAPS in the genera Acacia, Hakea and Pinus (Richardson et al. 2020; van Wilgen et al. 2020), which pose a serious threat to the biodiversity, as they alter ecosystem processes and reduce local species richness (van Wilgen et al. 2008). The economic impacts caused by these IAPS in the region are also high (van Wilgen 2016), where historical costs for control over the past 20 years have amounted to ZAR 564 million (2015 values) (van Wilgen et al. 2016). These costs do not include control efforts of IAPS by private landowners and volunteers. 


\section{Identifying volunteer groups in the Western Cape}

To identify and map existing volunteer groups in the Western Cape managing IAPS, an online search (Google) was conducted using the following terms in English, isiXhosa and Afrikaans 'hack groups, volunteer groups, invasive alien species control, and friends' groups' in April 2019. Researchers, managers and other stakeholders in the conservation sector (e.g. the Botanical Society of South Africa (Botsoc), Custodians or Rare and Endangered Wildlife (CREW) and Environment Society of South Africa (WESSA) were also consulted and asked to report known volunteer groups in the Western Cape. A short document asking people to report known volunteer groups in the Western Cape was produced and shared on social media (Facebook) and independently shared by users with personal accounts and groups. This yielded more results than other search efforts. Snowballing (word-of-mouth referrals) methodology was also used to source additional volunteer groups whereby in interviews we asked volunteer group leaders to identify other groups known to them.

\section{Questionnaires}

The survey was conducted through two different online questionnaires using Google Forms. One was directed at volunteer groups and was completed by the group co-ordinators or group leaders and contained 30 questions (Supplementary material, Document 1), and the other was directed at individual volunteers and had 26 questions (Supplementary material, Document 2).

The volunteer group-related questionnaire aimed to better understand how the whole group functions and contained different questions relating to: 1 ) how and when the group was formed; 2 ) the motivation behind forming the group; 3 ) how the group operates; 4) how they measure success in managing IAPS; 5) whether there is a group budget, the source of funding and what the budget is used for; 6) whether the groups require additional support from government entities, landowners and non-governmental organisations (NGO's); and 7) challenges faced by the groups.

The questionnaire directed at individuals who volunteered for groups controlling IAPS in the Western Cape aimed to understand the motivations, values and practices of volunteers. This questionnaire covered themes such as: 1) how they joined the volunteer groups; 2) their initial reasons for participating in IAS management; 3) their current motivations to volunteer, 4) the primary positive experiences or benefits they get from volunteering, 5) how often they volunteer; 6) whether volunteering cost them anything financially; 7) whether they detect and report IAS; and 8) any challenges they faced as volunteers. The second section of this questionnaire captured the demographic profile of respondents such as age, location, education level and current or previous field of work.

Both questionnaires contained open and closed ended questions, each with an estimated completion time of around 15 minutes. The final questionnaires were piloted, and the responses from the pilot experiment were not used in the results. The questionnaire was shared by intermittent posting from August 2019 to May 2020 and participants could use a link to access the survey and participate voluntarily online or there was the option to organise a telephonic interview. Government entities and NGOs such as City of Cape Town Invasive Species Unit and WESSA assisted with the distribution of the survey link throughout their volunteer networks using a mixture of direct emails and social media posts. The online survey ran for ten months and was the format through which most responses were collected, with very few done by telephonic interview during the same period.

\section{Data analysis}

Most questions related to motivations and challenges were open-ended to avoid forced responses. There are several different ways of classifying motivations, but for the purpose of this study, motivations were grouped into a mixture of categories identified by Bruyere and Rappe (2007), Measham and Barnett (2008), and West et al. (2015). Our categories relate broadly to different environmental values, socio-cultural values, personal well-being and educational values (see Supplementary material, Document 3). Responses were categorised post hoc and were assigned into different categories. Responses that were difficult to classify or that did not fall into any of the pre-determined categories were then assigned to the 'other' category (i.e. 'the managing authority Iname withheld] and other state environmental entities, including provincial and local structures, are not doing their job to conserve and protect the Lourens River riverine area').

\section{Ethics}

The necessary ethical clearance to conduct the research was obtained from the REC: Humanities at Stellenbosch University - Project number: 9578. All ethical standards were adhered to. An informed consent was obtained from all participants and anonymity was assured.

\section{Results}

\section{Volunteer groups}

We identified 52 volunteer groups (Supplementary material, Document 4); of these, we received 26 
completed responsesfromvolunteergroupco-ordinators and 56 responses from individual volunteer members. Most of the volunteer groups are concentrated within the city of Cape Town, with some groups in smaller towns scattered throughout in the rest of the province (Figure 1). The geographical spread of the groups has a full coverage of the Western Cape (with the furthest distance between Knysna and near Clanwilliam being over $500 \mathrm{~km}$, but some groups were less than $10 \mathrm{~km}$ apart). The fynbos biome was more represented than other biomes and most groups were situated in and around larger towns and cities in the region.

The oldest volunteer groups were initiated in the early 1980s. Many groups (43\%) were triggered by the expansion of IAPS and members realising the need to stop their spread (Figure 2). For example, one group co-ordinator highlighted their motivation for starting the group as 'The overwhelming growth of alien invasive in the Pledge Nature Reserve after the June 2017 fires'. The second-most important motivation for the groups was the need to preserve nature and biodiversity (20\%). For example, 'Elsies Peak was at that time a forest of invasive species. We wanted the fynbos back'. Moral obligation (14\%) also played an important role in forming some volunteer groups, for example, one group's motivation was to 'To put back something to Nature', while another group leader said, 'We love and care for this place'. This was followed by the need to preserve ecosystem services (11\%). Other groups (6\%) felt the need to get involved and protect important cultural and biodiversity sites. For example, 'Getting involved with the arboretum to formulate a draft management plan within the fynbos environment envisaged for the future. Focus on heritage, recreation and management'. While some groups $(6 \%)$ were initiated due to their desire to preserve environmental aesthetics.

The volunteer groups vary considerably in their size (maximum of 50 members and minimum of two members) with a mean of 12 members per group (Figure 1). Most groups met once a week, mainly during spring, summer and autumn. The average distance that members of the groups travelled to the sites where they worked was $8.6 \mathrm{~km}$ with the maximum being $75 \mathrm{~km}$ and the minimum being $1 \mathrm{~km}$. Half of the groups spent about three hours in the field controlling IAPS and the other half spent five or more hours when they met.

Most of the groups (60\%) also conduct other social and environmental activities such as environmental education, drawing up land use plans, restoring indigenous species and participating in river clean-ups, with an average of $20 \%$ of their time spent on IAS control. Groups prioritised work sites based on infestation densities, ease of plant identification and the terrain within their respective areas.

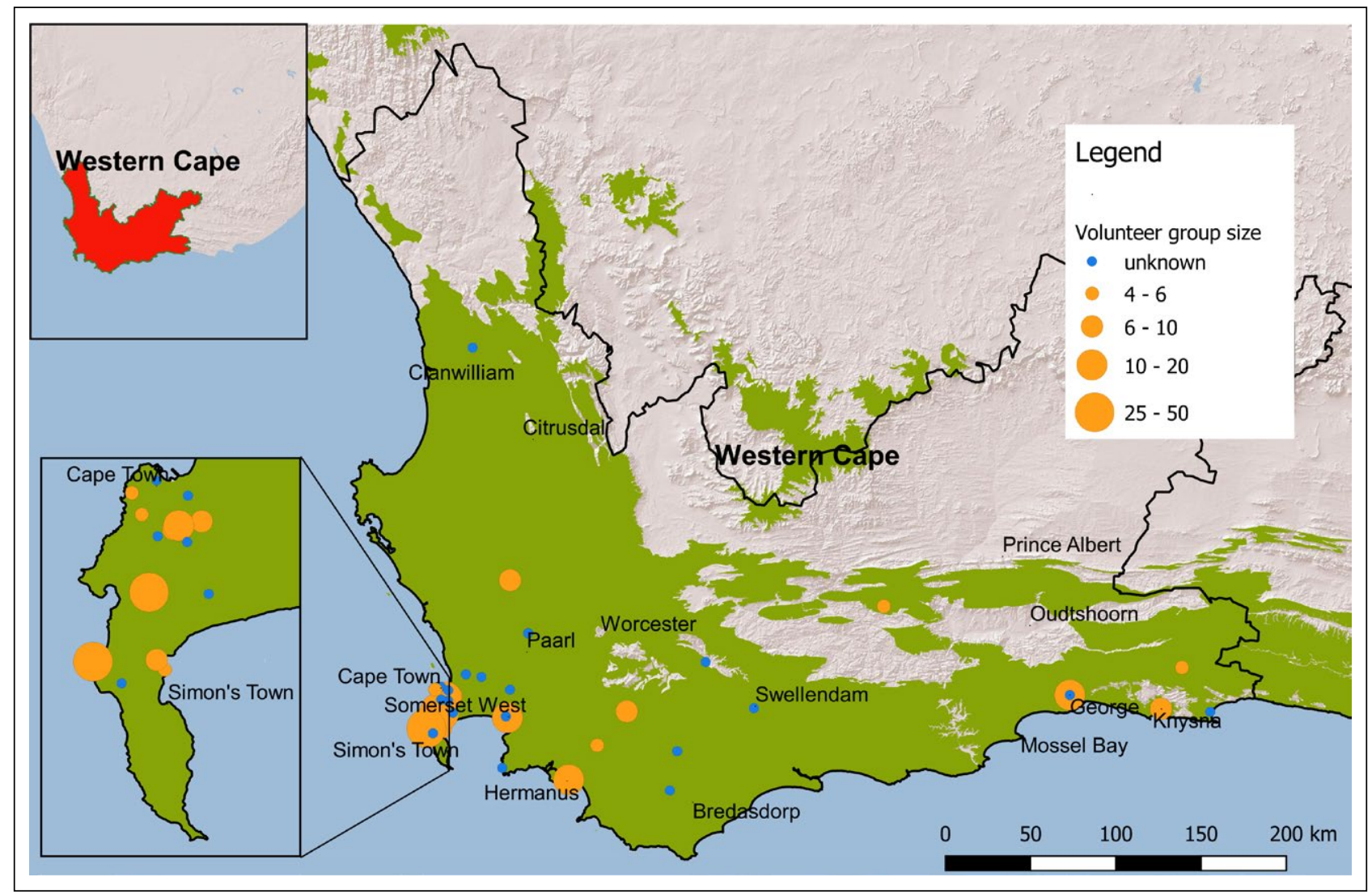

Figure 1. Identified volunteer groups (52) in Western Cape of South Africa. Groups that participated in the survey (26) are indicated by circles that also show group sizes (individual members per group). Groups that did not participate in the survey are indicated by blue circles. The green area on the map represents the fynbos biome. 


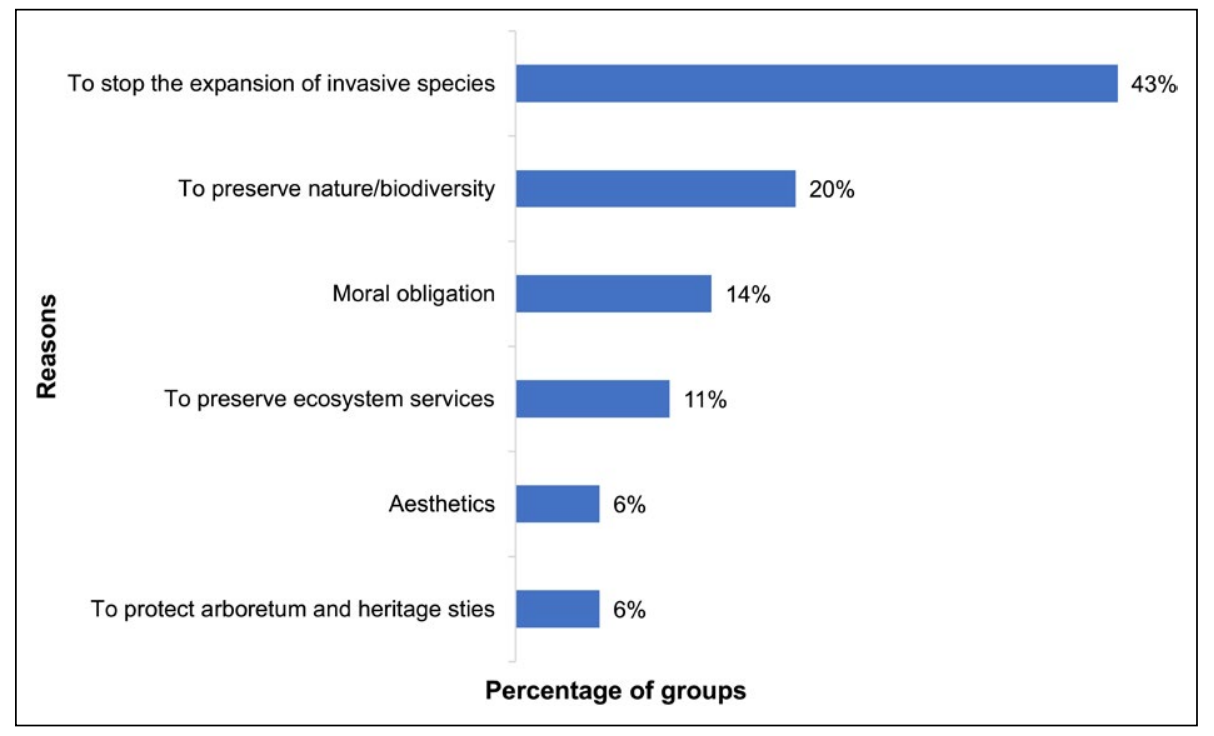

Figure 2. Motivations $(n=35)$ for forming volunteer groups that remove alien invasive plants in Western Cape, South Africa.

Almost all the groups concentrated their effort to control and reduce the spread and impact of widespread invasive woody trees such as: Acacia saligna (Port Jackson), Acacia mearnsii (black wattle), Acacia longifolia (golden wattle) and Acacia cyclops (rooikrans). Some groups also controlled emerging species with low population densities listed as Category 1a on South Africa's NEM:BA Act such as Spartina alterniflora (smooth cordgrass), Lythrum salicaria (purple loosestrife) and Melaleuca species (Supplementary material, Document 5). Almost all the groups used integrated control, combining manual removal and chemical control with herbicides at the site. However, only $16 \%$ of the groups indicated that they have qualified Pest Control Operators (PCO) in their groups. A PCO is someone who is trained and qualified to use herbicides to control IAPS.

Most groups (90\%) indicated that they do not collect any data on their management implementation. The groups mostly relied on visual assessment to measure progress on their management interventions.

\section{Estimated value of contributions by volunteer groups}

The majority (68\%) of the groups operated with no group budget, while the rest raised their own funds with a mean budget of ZAR 2923 per month, equivalent to ZAR 26307 per year (minimum ZAR 1000 and maximum ZAR15 000 per month). Generally, there was no assistance from government entities, municipalities or NGOs, except for herbicide supply for some groups (46\%). The money raised by groups was mainly for wages (for additional labour) and tools.

We used the data submitted by 26 volunteer groups that participated in the survey to estimate the equivalent total labour value contributed by these groups (26) to control IAPS in Western Cape drawing on WfW standards.
The estimate of the equivalent cost if it were done by WfW teams was calculated as: Number of hours worked by each group $\times$ number of volunteers $\times$ number weeks worked by the groups each year = the labour hours per group per year $\times$ by the general worker wage rate used by the $\mathrm{WfW}$ program. The totals for all 26 groups were added together and resulted in $=$ ZAR 5106241 (equivalent to USD 0.32 million). In considering all groups this number is probably closer to 10 million ZAR per annum.

The area of land cleared was calculated as: Total number of hours worked by the groups annually / number of hours to clear 1 ha at an assumed 5\% density as per WfW standards: $42165 / 8=5271$ ha cleared by 26 groups annually, again this is probably closer to 10000 ha if all groups are considered.

\section{Challenges mentioned by volunteer groups}

The top ranked challenge for most groups was to attract new members (23\%) (Figure 3). The challenge of extirpating the targeted IAPS (19\%) was ranked highly by the groups. Some groups had volunteers that are old (60 or more years) (16\%) who struggled with some aspects of controlling IAPS, which also links to difficult terrain $(12 \%)$. To a lesser the extent sustainability of long-term funding (6\%) was also viewed as a challenge. Historically bad control of IAPS, lack of support from government entities and landowners and fluctuating volunteer support were equally ranked as an issue (4\%) by only two groups. The 'other' category $(12 \%)$ included responses that relate to time constraints (volunteering time) as well as health and safety issues.

Most groups (72\%) indicated that they need extra support from government entities with the removal of biomass, for manpower to remove big trees, training for 


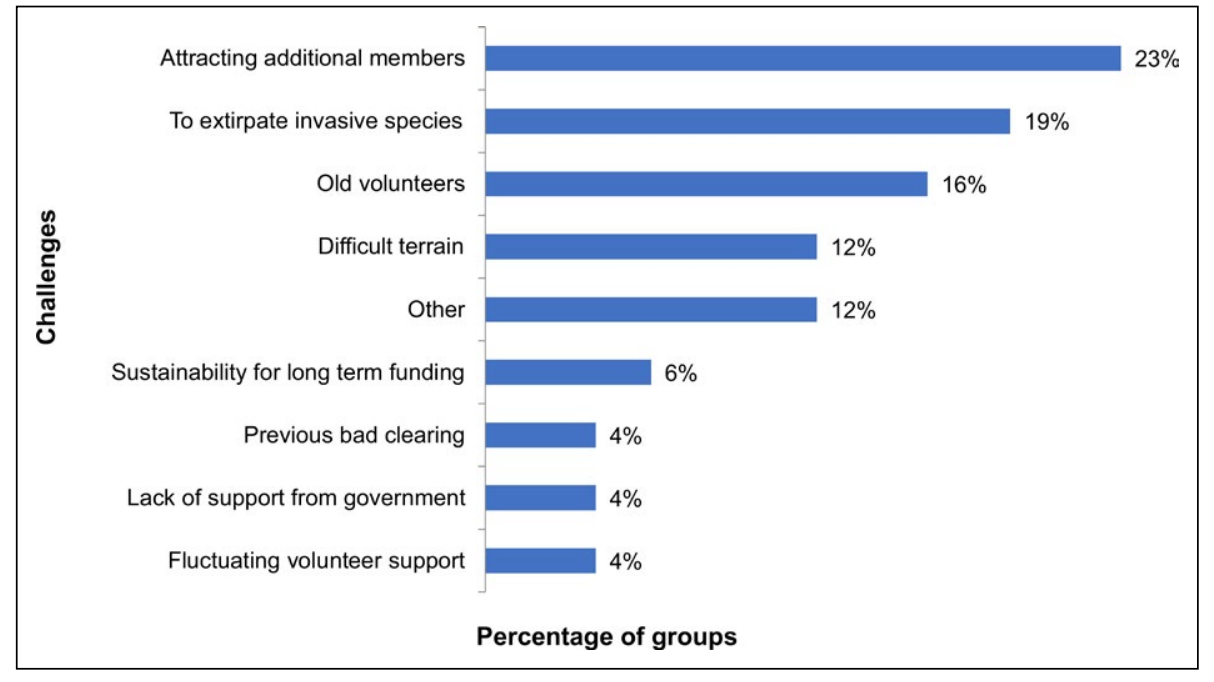

Figure 3. Challenges $(n=26)$ faced by volunteering by groups in the management of invasive alien plants in Western Cape, South Africa. new group members, as well as for extra funding, tools, labour and herbicide.

\section{Volunteer profiles}

Respondents' ages ranged between 24 and 83, with a mean age of 56. Most respondents (32\%) had been volunteering for five years or more, while $(30 \%)$ had been volunteering for three to four years and 38\% for one year and less. Most respondents were highly educated with the minimum education level being matric (completed high school) and some had a PhD. Eightytwo per cent of respondents had a degree (bachelors to $\mathrm{PhD})$. Six percent of respondents were employed in the environmental sector.

Most volunteers (31\%) initially got involved to stop the expansion of IAPS and to preserve nature (18\%). The desire to protect nature (moral obligation, environmental values) played an important role for some volunteers to join the groups $(25 \%)$. For example, one volunteer said, 'I wanted to contribute something to environmental protection', whereas another said, 'I take much from nature and want to give back'. Enjoyment and socialising (8\%) also triggered some volunteers to take part in IAPS management. Aesthetics (3\%), preserving ecosystem services ( $8 \%)$, exercise $(4 \%)$ and education awareness $(2 \%)$ were ranked as the last four initial motivations to get involved in IAPS management. The 'other' category included one response associated with looking for something useful to do because they were retired.

The initial motivations for volunteers to get involved in IAPS management were often different to the current motivations (Figure 4). Forty-six per cent of the volunteers felt their motivations had changed over time, in particular, their motivations changed from social reasons to contributing towards protecting nature and sharing their knowledge.

In answer to the question on current motivations to remain involved in the management of IAPS, many

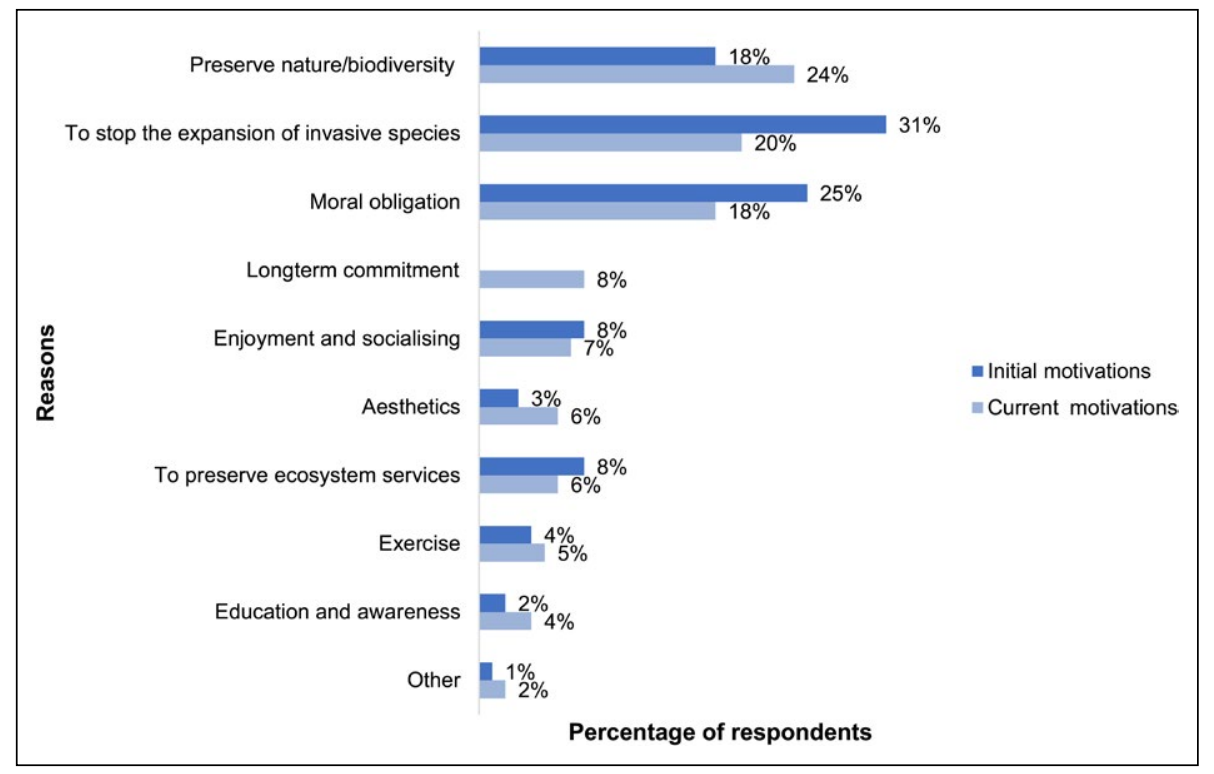

Figure 4. Reasons for initial engagement $(n=71)$ in volunteering and the current motivations $(\mathrm{n}=$ 86) for volunteers to be involved in the management of invasive alien plant species in Western Cape, South Africa. 
respondents said they were volunteering to preserve nature and biodiversity (24\%) and to stop the expansion of IAS (20\%) (Figure 4). Some responses (18\%) were linked to moral obligation. These include responses such as 'It would be a shame to lose our indigenous species' and 'I care very much about nature'. A few volunteers $(8 \%)$, said they have been doing this for many years and it is very difficult to give up as they can see some progress (longterm commitment): 'Difficult to give it up after 16 years'. Some volunteers (7\%) were more interested in socialising, while others $(6 \%)$ were doing it for aesthetic reasons and to preserve ecosystem services. There were also reasons relating to exercise $(5 \%)$ and education and awareness (4\%) (teaching and learning from others about IAS). Two responses that were difficult to classify into any of the mentioned categories (included in the 'other"' category) were mostly related to poor implementation by state institutions, for example, 'the managing authority [name withheld] and other state environmental entities, including provincial and local structures, are not doing their job to conserve and protect the Lourens River riverine area'.

Over a third of volunteers (38\%) identified a great sense of achievement and progress (i.e. reduction in IAPS numbers and recovery of indigenous vegetation) as the primary positive experience they get from volunteering. The second-most listed positive experience by volunteers was the sense of camaraderie and spending time with like-minded people (20\%). For example, one volunteer said, 'We have a lovely friendly group of volunteers; we laugh as we work, it is healthy to be outdoors in the fresh air; we get exercise and all of this leaves us with a really good feeling'. Getting some exercise and being outdoors (27\%) was also identified as an important primary benefit by volunteers. Other volunteers $(15 \%)$ were happy with knowing that they are making a difference by giving something back to nature, teaching others about IAS and at the same time learning from others. For example, one volunteer said 'The satisfaction of knowing I'm doing something to contribute to benefiting society, as well as nature. Not only for now, but for future generations', while another said, 'I get a great sense of achievement, teaching the volunteers about invasive and indigenous species and also learning from others.'

On average, respondents volunteered once a week to clear IAPS, depending on their availability and most volunteers $(54 \%)$ said they would do more if they had the time. Most respondents (54\%) indicated that volunteering does not cost them anything financially while others $(46 \%)$ said they spend money on transport (between their home and the site) and membership fees.

Most volunteers (82\%) said that they do detect and report IAS. Most sightings were reported to group leaders $(54 \%)$ and on iNaturalist (11\%). For example, in 2019, the Friends of Tokai discovered Callitris rhomboidea (Oyster Bay pine), which is currently not listed on NEM:BA and this represents the first record of this species in the region. Other volunteers $(29 \%)$ reported their sightings to different relevant local environmental authorities.

\section{Challenges faced by volunteers}

Most respondents (39\%) said that they do not face any challenges, while some (23\%) mentioned challenges related to time constraints (they feel they do not volunteer enough due to other commitments) (Figure 5). Lack of coordination and support from government management institutions and landowners was another important barrier identified by volunteers $(13 \%)$. For example, one volunteer said, 'Better co-operation between official bodies involved with alien vegetation management and volunteer groups is needed. Though we engage with SANParks and let them know what we are planning, we've had an instance where we spent a day clearing with volunteers, only to find that the site was already earmarked by SANParks and cleared by them the week after. We could have spent our time a lot

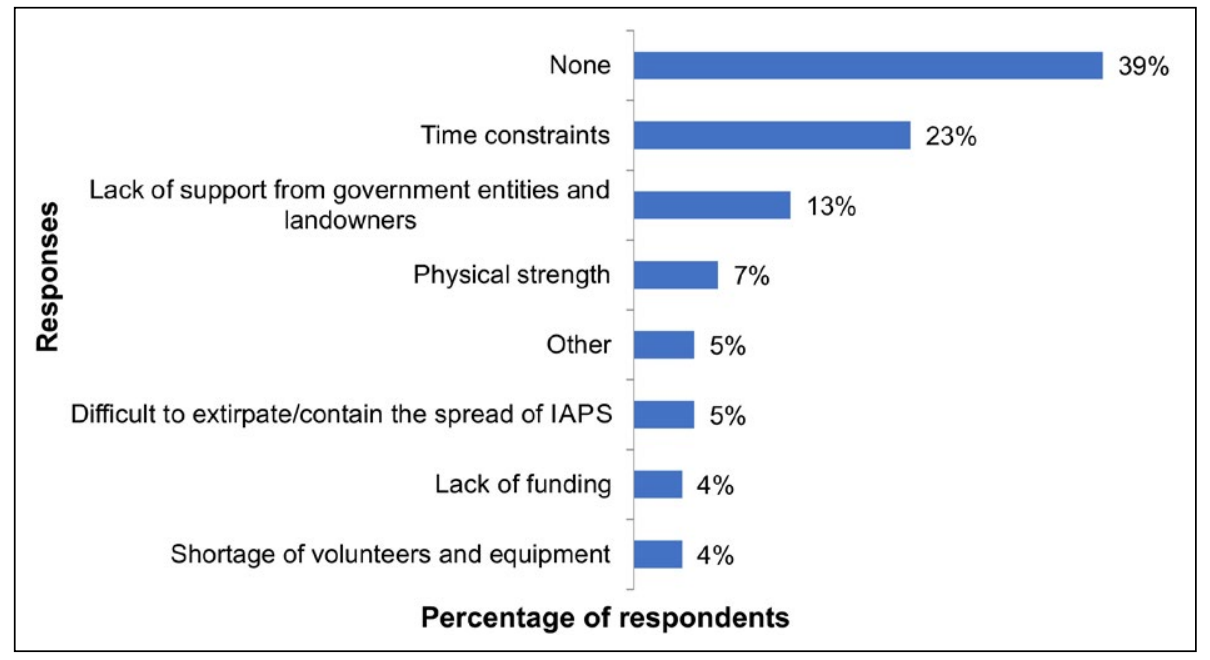

Figure 5. Challenges $(n=56)$ faced by individual volunteers in the management of invasive alien plant management in Western Cape, South Africa. 
better!' Another volunteer said, 'There are just too many invasives and no help from government. From emails it is apparent to me that [name withheld] is battling to get CapeNature to send us a team of helpers'. Physical strength $(7 \%)$ was ranked as a challenge by a few volunteers. Some volunteers are old and unable to get to some areas, especially those with difficult terrain. Some 'other' (5\%) responses were also mentioned, for example 'I prefer to operate as an individual - more flexibility for targeted work'. The challenge of extirpating or even containing the spread of IAPS was ranked the bottom three motivations by volunteers (5\%). For example, one volunteer said, 'Sometimes it feels that our small group is never going to be able to succeed, there are just too many invasives and no help from government'. Lack of funding and shortage or fluctuating support of volunteers was identified as the last two challenges identified by volunteers $(4 \%)$.

\section{Discussion}

\section{Identifying and promoting volunteer groups}

In this study, we established a list of 52 volunteer groups controlling IAPS in South Africa's Western Cape province (see Supplementary material, Document 4). Half of these groups did not participate in the survey and it is therefore unknown if they currently exist or not, or if our survey simply did not reach these groups. The geographical spread of the groups has a full coverage of the Western Cape, with volunteering groups in fynbos biome being more represented than other biomes (Figure 1). Interestingly, this biome corresponds closely with invasion hotspots in South Africa, and is an area with a long history of research and management of IAS (Bennett \& van Sittert 2019; van Wilgen et al. 2020). Interest in the management of biological invasions and preserving unique and famous indigenous fynbos species is also stronger in this region than elsewhere in the country (Bennett \& van Sittert 2019).

Volunteer groups also seems to be more closely associated with larger towns and cities in the region. Half of the groups that participate in the survey are estimated to clear approximately 5300 ha of land annually although if all groups are considered this is more likely to be 10000 ha. This shows a huge commitment from these volunteer groups in stopping the expansion of IAPS. However, to do this effectively, there needs to be better voluntary engagement between groups, conservation managers and other relevant actors (see Crall et al. 2010).

Volunteer initiatives could be co-ordinated and focus on areas that are lightly invaded while the state-run management programmes could focus in highly invaded areas. Formal state-run management programmes can also work on projects or species that require chemical control and extensive labour force to remove IAPS, removing this burden from volunteer groups. Assessing the distribution and contributions of volunteer groups and to IAPS management should also be conducted elsewhere in South Africa, and in other countries. Volunteer groups could also engage more with scientists to produce useful research moving forward.

\section{The benefits of volunteer groups and volunteering}

Volunteers contribute directly to the control of IAPS thus providing valuable services for the state, landowners and broader society (Pagès et al. 2019). This is evident from our results where we estimated the groups to clear approximately 5300 ha of land with estimated labour value of ZAR 5.1 million annually when aligned with formal WfW rates and control programmes. Most volunteers were also engaged in detecting and reporting IAPS, which is another valuable contribution for management of biological invasions.

Over and above the actual detection and clearing of IAPS, volunteers can possibly play an important role in promoting awareness and social learning about IAPS among themselves and to the public (Shackleton et al. 2019). This could result in a change in the knowledge and perceptions of the public and volunteers themselves with respect to IAPS (Shackleton et al. 2019), which is important for future management.

At the same time volunteers themselves gain fulfilment and build their social capital by meeting new people and making friends, giving something back to nature by helping to stop the expansion of IAPS (Figure 4) (Measham \& Barnett 2008; Geoghegan et al. 2016). Many aspects of volunteering, as indicated in this and other studies globally, can contribute to psychological and physical well-being as well (Koss \& Kingsley 2010; Molsher \& Townstead 2016).

\section{Volunteers' motivations for controlling IAS}

Volunteers have a variety of different motivations and it is important for managers implementing IAPS control initiatives to have a sound understanding of volunteers' knowledge, needs and motivations (Measham \& Barnett 2008; Geoghegan et al. 2016; Ganzevoort et al. 2017). Knowing and addressing volunteers' needs can help with keeping volunteers motivated as well as aid with promoting initiatives and attracting new members.

Most volunteers ranked environment-related motivations higher than social-related motivations as both 
their initial and current motivations. This is in accordance with previous studies where the preservation of the natural environment is noted to be the central motivation for volunteers (e.g. Hobbs \& White 2012; Ganzevoort et al. 2017; Pagès et al. 2019). It also shows the importance of volunteers and their connection with nature (Ganzevoort et al. 2017).

With time, respondents' motivations changed from social reasons to making a contribution towards protecting the natural environment and learning and sharing their knowledge (Figure 4). This suggests that volunteering makes people more environmentally aware and proactive (Ganzevoort et al. 2017).

Respondents were encouraged by seeing reduction of IAPS and recovery of indigenous vegetation, as a result this was identified as a primary positive experience they get from volunteering. Our study therefore supports the notion that the recovery of indigenous vegetation is very encouraging, and a key reason for the long-term commitment of volunteers (Pagès et al. 2019), especially for those that have been involved in volunteering work for long periods.

\section{Challenges to volunteering and the way forward}

The biggest challenge faced by groups was attracting new volunteers to join the groups (Figure 3). This may be linked to the lack of advertising by groups as well as difficulty making contact, which was an issue was reinforced during data collection. The moderate number of responses received (26 out of 52 groups) in this study was because many groups were untraceable due to invalid contact details and/or non-existent group websites and pages on the internet or the fact that some of these groups might no longer exist. This could also mean that the number of extant volunteer groups is lower than 52 .

According to Ganzevoort et al. (2017), social media and websites of environmental groups are the best platforms for the promotion of nature-based citizen science projects. More volunteer groups should take advantage of the available online and social media platforms to publicise their groups and regularly share the work that they are doing. Volunteers and groups can further use social media to attract more volunteers, aid with co-ordination and increase awareness about IAS (Blood 2016). However, this may potentially require on-going technical and administrative support (Pagès et al. 2019).

Another important challenge to volunteering identified by group leaders and individual volunteer respondents related broadly to co-ordination between and longterm support from government entities, NGOs and landowners. It is recommended that there is improved communication and coordination between all stakeholders involved in IAPS management and volunteers to improve and support the work done by volunteer groups (Ellwoodd et al. 2017).

According to Dechoum et al. (2019), volunteers can be helpful across multiple scales, but their effort must be combined with other stakeholders' efforts to ensure long-term success and improved outcomes, which would also address another challenge of making little progress (Figure 3 and 5). The groups indicated that they require support from government entities, landowners and Non-Government Organisations (NGOs) mainly for removal of biomass, manpower to remove bigger plants, tools, training for new members and provision of herbicide. For this to happen, we recommend a better engagement between groups and other actors and relevant platforms for this need development.

The coordination of multiple volunteer groups using umbrella partnerships and other actors seems particularly successful, similarly appointing a co-ordinator to support groups could also help (Pagès et al. 2019). A co-ordinator should create a database of all groups across the country, respond to their needs and aid with promotion that helps with recruitment of volunteers. Linking volunteer groups and schools could lead to beneficial education and learning opportunities for children and potentially increase interest in volunteering in future generations. The co-ordinator could also assist with planning control activities and the prioritisation of species and areas. For example, the Custodians of Rare and Endangered Species (CREW), where citizens assist with the monitoring of threatened plant species (Araya et al. 2009; Young 2009), and SANParks honorary rangers, are both useful models for developing co-ordinated volunteer networks in South Africa.

Importantly, the co-ordinator should reduce the bureaucracy while supporting groups, integrating volunteers' work to national and local programmes dealing with biological invasions. Their role could link the groups together and bridge the work done by volunteers with science, policy and management (Novoa et al. 2018; Abrahams et al. 2019). It could also help to promote these groups and the work they do in the wider community, increasing awareness of IAS. This could also help to monitor and collect data to account for the valuable contributions of volunteers to controlling IAS at regional and national levels (Delaney et al. 2008; Dechoum et al. 2019).

Most volunteer groups work on containing established invasive Australian species (the most widespread invasive taxa in South Africa) with very few groups working on emerging IAS or populations with low densities (for example, Lythrum salicaria, Melaleuca sp. and Spartina alterniflora). In the long term, early detection and extirpation of IAS is the most cost-effective management 
option (Rejmánek \& Pitcairn 2002; Fitzpatrick et al. 2009). Volunteers offer an avenue for detecting and containing the spread of IAPS while the populations are still small and localised (e.g. Delaney et al. 2008; Dechoum et al. 2019). It would be beneficial if volunteers can be trained on relevant species identification and effective ways of controlling IAPS to improve their early detection and extirpation efforts (Gallo \& Waitt 2011). Volunteers should also be trained about the correct use of herbicides, including health and safety measures, to avoid possible health effects (Macfarlane et al. 2013). The use of mobile apps such as iNaturalist should also be utilised for species identification and to connect citizens and experts in the field (Silvertown et al. 2015).

\section{Conclusion}

In conclusion, it is evident that volunteers play an important role in IAPS management and are likely to continue doing so into the future. Better co-ordination and engagement between volunteers and mandated authorities on science, policy and management are required to improve the groups and keep volunteers motivated about managing IAPS.

\section{Acknowledgements}

The South African Department of Forestry, Fisheries and the Environment (DFFE) are thanked for funding, noting that this publication does not necessarily represent the views or opinions of the DEFFE or its employees. We also thank and acknowledge the South African National Biodiversity Institute's Biological Invasions Directorate, the volunteers who participated in our survey and our reviewers. In particular, we thank John Wilson, Mlungele Nsikani and Thulisile Jaca for helpful comments on the manuscript. We would like to thank the DSI-NRF Centre of Excellence for Invasion Biology.

\section{Competing interests}

The authors declare that they have no financial or personal relationships that may have inappropriately influenced them in writing this article.

\section{Authors' contributions}

NJ, RTS and JM conceived the study. NJ collected and analysed the data and drafted the article. All authors gave final approval of the version published in Bothalia.

\section{References}

Abrahams, B., Sitas, N. \& Esler, K.J., 2019, 'Exploring the dynamics of research collaborations by mapping social networks in invasion science', Journal of Environmental Management 229, 27-37. https://doi.org/10.1016/j.jenvman.2018.06.051.

Araya, Y.N., Schimedel, U. \& von Witt, C., 2009, 'Linking 'citizen scientists' to professionals in ecological research, examples from Namibia and South Africa', Conservation Evidence 6, 11-17.

Bennett, B.M. \& van Sitter, L., 2019, 'Historicising perceptions and the national management framework for invasive alien plants in South Africa', Journal of Environmental Management 229, 174-181. https://doi.org/10.1016/j.jenvman.2018.07.029.

Blood, K., 2016, 'Use of social media fo sharing invasive species information', Twentieth Australasian Weeds Conference.

Bruyere, B. \& Rappe, S., 2007, 'Identifying the motivations of environmental volunteers', Journal of Environmental Planning and Management 50, 503-516. https://doi. org/10.1080/09640560701402034.

Crall, A.W., Newman, G.J., Jarnevich, C.S., Stohlgren, T.J., Waller, D.M., Graham, J., 2010, 'Improving and integrating data on invasive species collected by citizen scientists', Biological Invasions 12, 3419-3428. https://doi.org/ 10.1007/s10530-010-9740-9.
Dechoum, M.D., Giehl, E.L.H., Sühs, R.B., Silveira, T.C.L. \& Ziller, S.R., 2019, 'Citizen engagement in the management of non-native invasive pines: Does it make a difference?', Biological Invasions 21, 175-188. https://doi.org/10.1007/ s10530-018-1814-0.

Delaney, D.G., Sperling, C.D., Adams, C.S. \& Leung, B., 2008, 'Marine invasive species: Validation of citizen science and implications for national monitoring networks', Biological Invasions 10, 117-128. https://doi.org/10.1007/ s10530-007-9114-0.

Ellwood, E.R., Crimmins, T.M. \& Miller-Rushing, A.J., 2017, 'Citizen science and conservation: Recommendations for a rapidly moving field', Biological Conservation 208, 1-4. https://doi.org/10.1016/j.biocon.

Faulkner, K.T., Robertson, M.P., Rouget, M. \& Wilson, J.R.U., 2015, 'Understanding and managing the introduction pathways of alien taxa: South Africa as a case study', Biological Invasions 18, 73-87. https://doi.org: 10.1007/ s10530-015-0990-4.

Fitzpatrick, M.C., Preisser, E.L., Ellison, A.M. \& Elkinton, J.S., 2009, 'Observer bias and detection of low-density populations', Ecological Applications 19, 1673-1679. https://doi. org/10.1890/09-0265.1.

Gallo, T. \& Waitt, D., 2011, 'Creating a successful citizen citizen science model to detect and report invasive species', BioScience 61, 459-65. 
Ganzevoort, W., van den Born, W.R.J., Halffman, W. \& Turnhout, S., 2017, 'Sharing biodiversity data: citizen scientists' concerns and motivations', Biodiversity and Conservation 26, 2821-2837. https://doi.org/10.1007/s10531-0171391-z.

Geoghegan, H., Dyke, A., Pateman, R., West, S. \& Everett, G., 2016, 'Understanding motivations for citizen science. Final report on behalf of UKEOF, University of Reading', Stockholm Environment Institute (University of York) and University of the West of England. http://www.ukeof.org. uk/resources/citizen-science-resources/MotivationsforCSREPORTFINALMay2016.pdf. Accessed 17 May 2020.

Hobbs, S.J. \& White, P.C.L., 2012, 'Motivations and barriers in relation to community participation in biodiversity recording', Journal for Nature Conservation 20, 364-373. https://doi.org/10.1016/j.jnc.2012.08.002.

Hulme, P.E., Bacher, S., Kenis, M., Klotz, S., Kühn, I., Minchin, D., Nentwig, W., Olenin, S., Panov, V., Pergl, J., Pyšek, P., Roques, A., Sol, D., Solarz, W. \& Vilà, M., 2008, 'Grasping at the routes of biological invasions: a framework for integrating pathways into policy', Journal of Applied Ecology 45, 403-414. https://doi: 10.1111/j.13652664.2007.01442.x

Jeschke, J.M., Bacher, S., Blackburn, T.M., Dick, J.T., Essl, F., Evans, T., Gaertner, M., Hulme, P., Kühn, I., Mrugala, A., Pergl, J., Pyšek, P., Rabitsch, W., Ricciardi, A., Richardson, D.M., Sendek, A., Vila, M., Winte, M. \& Kumschick, S., 2014, 'Defining the impact of non-native species' Conservation Biology 28, 1188-1194. https://doi.org/10.1111/ cobi.12299.

Koss, R.S. \& Kingsley, J.Y., 2010, 'Volunteer health and emotional wellbeing in marine protected areas', Ocean \& Coastal Management 53, 447-453. https://doi.org/10.1016/j. ocecoaman.2010.06.002.

Macfarlane, E., Carey, R., Keegel, T., El-Zaemay, S. \& Fritschi, L., 2013, 'Dermal exposure associated with occupational end use of pesticides and the role of protective measures', Safety Health Work 4, 136-141. https://doi.org/10.1016/j. shaw.2013.07.004.

Measham, T.G. \& Barnett, G.B., 2008, 'Environmental volunteering: motivations, modes and outcomes', Australian Geographer 39, 537-552. https://doi.org/10.1080/ 00049180802419237.

Molsher, R. \& Townsend, M., 2016, 'Improving wellbeing and environmental stewardship through volunteering in nature', Ecohealth 13, 151-155. doi: 10.1007/s10393015-1089-1.

Novoa, A., Dehnen-Schmutz, K., Fried, J. \& Vimercati, G., 2017, 'Does public awareness increase support for invasive species management? Promising evidence across taxa and landscape types', Biological Invasions 19, 3691-3705. https://doi.org/10.1007/s10530-017-1592-0.

Novoa, A., Shackleton, R., Canavan, S., Cybele, C., Davies, S.J., Dehnen-Schmutz, K., Fried, J., Gaertner, M., Geerts, S., Griffiths, C.L., Kaplan, H., Kumschick, S., Le Maitre D.C., Measey, G.J., Nunes, A.L., Richardson, D.M., Robinson T.B., Touza, J. \& Wilson, J.R.U., 2018, 'A framework for engaging stakeholders on the management of alien species', Journal of Environmental Management 205, 286297. https://doi.org/10.1016/j.jenvman.2017.09.059.

Pagès, M., Fischer, A., van der Wal, R. \& Lambin, X., 2019, 'Empowered communities or "cheap labour"? Engaging volunteers in the rationalised management of invasive alien species in Great Britain', Journal of Environmental Management 229, 102-111. https://doi.org/10.1016/j. jenvman.2018.06.053.

Pimentel, D., Zuniga, R. \& Morrison, D., 2005, 'Update on the environmental and economic costs associated with alien-invasive species in the United States', Ecological Economics 52, 273-288. https://doi:10.1016/j.ecolecon.2004.10.002.

Rebelo, A.G., Boucher, C., Helme, N., Mucina, L., Rutherford, M.C., 2006, 'Fynbos Biome', In: Mucina, L., Rutherford, M.C. (Eds.), The Vegetation of South Africa, Lesotho, and Swaziland. South African National Biodiversity Institute, Pretoria, pp. 52-219.

Rejmánek, M. \& Pitcairn, M.J., 2002, When is eradication of pest plants a realistic goal. In: Turning the tide: the eradication of invasive species eds D. Veitch and M. Clout, pp. 249-253. Invasive Species Specialty Group of the World Conservation Union (IUCN), Auckland, New Zealand.

Richardson, D.M., Foxcroft, L.C., Latombe, G. et al., 2020, 'The biogeography of South African terrestrial plant invasions'. In: van Wilgen, B.W., Measey, J., Richardson, D.M., Wilson, J.R., Zengeya, T.A. (eds) Biological invasions in South Africa. Springer, Berlin, pp 65-94. https://doi. org/10.1007/978-3-030-32394-3_3.

Richardson, D.M. \& van Wilgen, B.W.'., 2004, 'Invasive alien plants in South Africa: how well do we understand the ecological impacts'?, South African Journal of Science 100:45-52.

Shackleton, R.T., Adriaens, T., Brundu, G., Dehnen-Schmutz, K., Estévez, R.A., Fried, J., Larson, B.M.H., Liu, S., Marchante, E. \& Marchante, H., 2019, 'Stakeholder engagement in the study and management of invasive alien species', Journal of Environmental Management 229, 88-101. https://doi.org/10.1016/j.jenvman.2018.04.044.

Shackleton, R.T., Le Maitre, D.C., van Wilgen, B.W. \& Richardson, D.M., 2016, 'Identifying barriers to effective management of widespread invasive alien trees: Prosopis species (mesquite) in South Africa as a case study', Global Environmental Change 38, 183-194. https://doi. org/10.1016/j.gloenvcha.2016.03.012.

Silvertown, J., Harvey, M., Greenwood, R., Dodd, M., Rosewell, J., Rebelo, T., Ansine, J. \& McConway, K., 2015, 'Crowdsourcing the identification of organisms: A case study of ispot', Zoo Keys 480, 125-146. https://doi. org/10.3897/zookeys.480.8803.

StatsSA, 2019, 'Midyear Population Estimate 2019. Population Estimates, July', https://www.statssa.gov.za/publications/P0302/P03022019.pdf. Accessed 05 June 2020.

Thomas, M.L., Gunawardene, N., Horton, K., Williams, A., O'Connor, S., McKirdy, S. \& van der Merwe, J., 2017, 'Many eyes on the ground: citizen science is an effective early detection tool for biosecurity', Biological Invasions 19, 2751-2765. https://doi.org/10.1007/s10530-017-1481-6. van Rensburg, J., van Wilgen, B.W. \& Richardson, D.M., 2017, 'The challenges of managing invasive alien plants on private land in the Cape Floristic Region: insights from Vergelegen Wine Estate (2004-2015)'. Transactions of the Royal Society of South Africa, 72, 207-216. https://doi.org /10.1080/0035919X.2017.1288175.

van Wilgen, B.W. \& Wannenburgh, A., 2016, 'Co-facilitating invasive species control, water conservation and pov- 
erty relief: achievements and challenges in South Africa's Working for Water programme', Current Opinion Environmental Sustaininability 19:7-17. https://doi.org/10.1016/j. cosust.2015.08.012.

van Wilgen, B.W., Fill, J.M., Baard, J., Cheney, C., Forsyth, A.T. \& Kraaij, T., 2016, 'Historical costs and projected future scenarios for the management of invasive alien plants in protected areas in the Cape Floristic Region', Biological Conservation 200, 168-177. https://doi.org/10.1016/j. biocon.2016.06.008.

van Wilgen, B.W., Reyers, B., Le Maitre, D.C., Richardson, D.M. \& Schonevegel, L., 2008, 'A biome-scale assessment of the impact of invasive alien plants on ecosystem services in South Africa', Journal of Environmental Management 89:336-349. https://doi.org/10.1016/j.jenvman.2007.06.015.

van Wilgen, B.W., Wilson, J.R., Wannenburgh, A. \& Foxcroft, L.C., 2020, 'The extent and effectiveness of alien plant control projects in South Africa'. In: van Wilgen, B.W., Measey, J., Richardson, D.M., Wilson, J.R., Zengeya, T.A. (eds) Biological invasions in South Africa. Springer, Berlin, pp 593624. https://doi.org/10.1007/978-3-030-32394-3_21.
West, S., Pateman, R. \& Dyke, A., 2016, 'Data submission in citizen science projects report for DEFRA (Project number PH0475)', https://www.york.ac.uk/media/sei/documents/ publications/projectreports/West-Pateman-Dyke-DEFRAData-Submission-in-Citizen-Science-Projects.pdf. Accessed 24 July 2020

Wilson, J.R., Measey, J., Richardson, D.M., van Wilgen, B.W. \& Zengeya, T.A., 2020, 'Potential futures of biological invasions in South Africa'. In: van Wilgen B.W., Measey, J., Richardson, D.M., Wilson, J.R., Zengeya, T.A. (eds) Biological invasions in South Africa. Springer, Berlin pp 917-946. https://doi.org/10.1007/978-3-030-32394-3_31.

Wilson, J.R.U., Ivey, P., Manyama, P. \& Nänni, I., 2013, A new national unit for invasive species detection, assessment and eradication planning, South African Journal of Science 109, 5-6. https://doi.org/10.1590/sajs.2013/20120111.

Young, S., 2009, 'Monitoring Threatened Species inSouth Africa: a review of the South African National Biodiversity Institutes Threatened Species Programme: 2004-2009', South African National Biodiversity Institute. http://www. sanbi.org/sites/default/files/documents/documents/tspreview.pdf. Accessed 28 May 2020. 


\section{Supplementary Material}

Only available online: doi: http://dx.doi.org/10.38201/btha.abc.v51.i2.s3 